University of Massachusetts Amherst

ScholarWorks@UMass Amherst

Chemistry Department Faculty Publication Series

Chemistry

1992

\title{
Determination of arsenic in a nickel alloy by flow injection hydride generation atomic absorption spectrometry
}

Julian Tyson

University of Massachusetts Amherst

C P. Hanna

University of Massachusetts Amherst

S G. Offley

Loughborough University of Technology

Follow this and additional works at: https://scholarworks.umass.edu/chem_faculty_pubs

Part of the Chemistry Commons

\section{Recommended Citation}

Tyson, Julian; Hanna, C P.; and Offley, S G., "Determination of arsenic in a nickel alloy by flow injection hydride generation atomic absorption spectrometry" (1992). Spectrochimica Acta Part B. 1303.

Retrieved from https://scholarworks.umass.edu/chem_faculty_pubs/1303 


\title{
Determination of arsenic in a nickel alloy by flow injection hydride generation atomic absorption spectrometry
}

\author{
C. P. Hanna and J. F. Tyson* \\ Chemistry Department, University of Massachusetts at Amherst, Amherst, MA 01003, U.S.A. \\ and \\ S. G. OfFley† \\ Chemistry Department, University of Technology, Loughborough, Leics., LE11 3TU, U.K.
}

(Received 30 January 1992; accepted 23 March 1992)

\begin{abstract}
The development of a method for the direct determination of trace arsenic quantities in nickel alloy digests, by flow injection hydride generation atomic absorption spectrometry, is described. An optimization study of the manifold and chemical parameters produced system performance, in terms of tolerance of the nickel matrix and sensitivity, such that matrix removal and pre-reduction of $\operatorname{As}(\mathrm{V})$ to $A s$ (III) prior to arsine generation were eliminated. Full recovery of the As(V) signal from a solution containing $5 \mathrm{ng} \mathrm{ml}^{-1}$ in the presence of $60 \mu \mathrm{g} \mathrm{ml}^{-1}$ nickel was obtained. Validation of the method was achieved by analyzing a British Chemical Standard (BCS) Certified Reference Material (CRM) \#346 IN nickel alloy containing arsenic at a concentration of $50 \mu \mathrm{g} \mathrm{g}^{-1}$. Following dissolution in nitric and hydrofluoric acids by a microwave assisted procedure, the only subsequent preparation required was dilution by the appropriate factor. Up to 60 injections $\mathrm{h}^{-1}$ may be made, with a detection limit of $0.5 \mathrm{ng} \mathrm{ml}^{-1}$ arsenic ( $250 \mathrm{pg}$ absolute) as $\mathrm{As}(\mathrm{V})$ in a $500 \mu \mathrm{l}$ sample. The peak height characteristic concentration is $0.46 \mathrm{ng} \mathrm{ml}^{-1}$, with a relative standard deviation of $3.5 \%$ for a $10 \mathrm{ng} \mathrm{ml}^{-1} \mathrm{As}(\mathrm{V})$ standard $(n=6)$.
\end{abstract}

\section{INTRODUCTION}

THE DETERMINATION of elements, such as arsenic, which form volatile hydrides by the generation, separation and decomposition of this derivative is a well-established analytical procedure [1,2]. As with any analytical method, there are possibilities for interferences from other components of the system. However, as the procedure incorporates chemical derivatization of the analyte, there are additional possibilities for interferences in hydride generation (HG) atomic spectrometry. The most severe interferences would appear to be due to the presence of transition metals, which when precipitated as finely divided metal by the hydride generating reagent, cause decomposition of the hydrides [3, 4]. These interferences have been extensively studied by several research groups [2] and various methods proposed for their elimination, including the addition of masking agents, re-optimization of reaction conditions and separation of the appropriate matrix components.

Although the use of continuous-flow HG systems had been described as early as 1976 [5], the motivation for the development of such procedures appears to have been the need to automate the system rather than reduce interference effects. Although the superiority, in terms of interference reduction in the determination of arsenic and selenium, of the continuous flow mode has been demonstrated by PIERCE and Brown in 1977 [6], it was not until 1982 with the appearance of a flow injection (FI) HG method for bismuth devised by Asтrom [7], that the benefits of the continuous flow format for decreasing interference effects were considered an important benefit. In this particular study, it was shown that the relative amount of copper or nickel which could be tolerated was increased by 2-3 orders of magnitude compared with the tolerance of a batch procedure. This finding has been confirmed by several independent research groups [8-11] and is one of the features that has contributed to the development

*Author to whom correspondence should be addressed.

†Present address: Unicam Analytical Systems, Unicam LTD., York Street, Cambridge, CB1 2PX, U.K. 
of a commercial FI-HG system [12]. The flow injection hydride generation literature has recently been reviewed as part of a larger review of flow injection atomic spectrometry [13], from which it may be discerned that there is considerable interest in the optimization of the manifold design and operating conditions, but that so far a consensus as to what these design features and operating parameters might be has not yet appeared.

To some extent the variations in the systems described in the literature are due to the differences in performance of the various atomization devices used. Leaving aside the use of graphite furnaces, which have been shown to be effective for both trapping gaseous hydrides and for the subsequent decomposition to atoms [14], several different atomization devices have been used including tubes in flames, flames in tubes, furnace heated tubes and inductively coupled plasmas. In some instances, the extent of atomization has been shown to depend on the presence of small amounts of oxygen which in turn influences the partial pressure of hydrogen radicals, needed for the production of atoms from some hydrides [15]. Although some of the flow injection systems described have used an air segmented carrier stream [16], the primary purpose of this feature appears to have been the decreased dispersion arising from transport in the manifold tubing.

Although there is agreement on the use of sodium tetrahydroborate(III) solution as the reducing agent, there is not universal agreement on the order of addition of reagents. Most manifolds described in the literature add an acid stream to the stream carrying the sample before merging the borohydride stream, but one or two papers describe the reverse order of reagent addition [17]. Other parameters which have been the subject of optimization studies include type of acid used and the concentrations of reagents, which in flow injection procedures has implications for the relative flow rates in merging stream manifolds.

Flow injection also allows optimization of the volume injected and the residence time and in common with batch or continuous flow procedures requires optimization of design of gas-liquid separator, argon flow, atomizer design and operating temperature, transfer tube dimensions and the means by which water is removed from the transfer tube. As there are several possible figures of merit (such as sensitivity and throughput) including the options of multi-element determinations and determinations in the presence of potentially interfering species, such as transition metal ions, it is perhaps not surprising that there is little agreement on "the best" conditions. Although it might be argued, therefore that each case should be considered separately, not all laboratories can afford to devote time to extensive method development. Fortunately, the results of a comprehensive optimization study of flow injection hydride generation by workers with substantial experience of all aspects of hydride generation, has recently become available [18].

In common with many previous optimization studies, a single cycle alternating variable search procedure was adopted with a composite figure of merit, which in this case, involved absolute and relative sensitivities, sampling frequency and consumption of reagent and sample. Although the statistical validity of this approach is open to question [19], it is widely adopted by analytical chemists when investigating systems for which a large number of possibly interacting variables are involved and for which the stability of the response may not be under complete control. The tube in flame atomizer provides a good example of this latter problem, as quite large changes in sensitivity can be observed on a day to day basis [20]. However, it has been shown that results indistinguishable from those obtained with the aid of a simplex optimization procedure can be obtained with a version of the univariate search methods in which two or three cycles of each variable are made [21] and thus the results obtained by a single cycle search, which starts from values for the variables chosen on the basis of previous experience and a good understanding of the underlying chemistry and physics of the system, may well give optimum values not far from the co-ordinates of the maximum in the factor space.

Although the possibilities for interference effects in hydride generation are well 
known, it is not possible in any general study to investigate all possible interference effects. Pierce and Brown make an heroic effort in the case of arsenic and selenium [6] which clearly showed the superiority of an automated system over a batch method. Welz and Schubert-Jacobs [18] illustrated their optimization study with the measurement of arsenic in the presence of nickel and the measurement of selenium in the presence of copper and again a clear superiority over the batch procedure was demonstrated. The former determination presents something of a challenge for the situation in which the arsenic is to be measured in an alloy whose major component is nickel for two reasons. Firstly, the interference tolerance of previously reported FI procedures for As are not high enough to allow removal of the nickel interference by dilution and secondly any dissolution procedure is likely to produce arsenic in the +5 oxidation state for which the sensitivity of determination is considerably decreased in comparison to that of As(III).

Previous reports of the use of FI procedures for this analysis have used on-line matrix removal with a mini-column of cation exchange resin [17] (a procedure which has also been successfully applied to the determination of selenium in copper [22]) as well as an on-line stopped flow pre-reduction with iodide solution [23]. Although accurate results have been reported, the manifolds were of considerable complexity and of sub-optimal design for flow injection work particularly with respect to the gas-liquid separators used. Many of the previously reported FI-HG systems used gas-liquid separators designed for use in continuous flow manifolds. As the measurement is made on a steady state signal, the volume of the separator has little or no effect on the magnitude of the signal obtained. However, for a FI system, in which vapor generation is a transient process, the volume of the gas-liquid separator is clearly an important design criterion.

The aim of the present work was to use this analysis to demonstrate that further improvements in performance with respect to sensitivity and interference tolerance are possible with a hydride generation system designed specifically for FI procedures. Furthermore, that a considerable simplification over previously reported methods is possible.

\section{EXPERIMENTAL}

\subsection{Apparatus}

2.1.1. Flow injection-hydride generation AAS equipment. A Perkin-Elmer 3100 atomic absorption spectrometer equipped with a Perkin-Elmer arsenic hollow cathode lamp operated at $18 \mathrm{~mA}$ was used for all determinations. A spectral bandpass of $0.7 \mathrm{~nm}$ at the $193.7 \mathrm{~nm}$ arsenic spectral line was used.

Pumps, pump tubing, manifold tubing, gas-liquid separator, injection valve and other FI equipment used were supplied by Perkin-Elmer in their FIAS 200 flow injection atomic spectroscopy system. The FI manifold constructed for hydride generation is shown in Fig. 1. The gas-liquid separator was a cylindrical chamber partially filled with glass beads $(3 \mathrm{ml}$ total volume), with a separate connection pumping spent liquid to waste.

2.1.2. Computer control. All variables of the analysis were controlled on the FIAS 200 system through a personal computer (Digital Equipment Corporation DECstation $316 \mathrm{sx}$ ). The computer also performed all data processing.

\subsection{Reagents}

Reagent grade water produced by an E-Pure water system (Barnstead) was used in all solutions. Reagent grade concentrated hydrochloric acid $\left(38 \% \mathrm{~m} \mathrm{~m}^{-1}\right.$, density $=1.19$, Fisher Scientific) was used throughout the study. Sodium borohydride solutions were prepared fresh daily by dissolving the appropriate amount of sodium borohydride powder (Baker) in $0.1 \%$ $\left(\mathrm{m} \mathrm{v}^{-1}\right)$ sodium hydroxide $(\mathrm{FW}=40.00$, Fisher Scientific). The resulting solution was filtered by suction through \#42 Whatman filter discs prior to use. A $1000 \mathrm{mg} \mathrm{ml}^{-1}$ stock solution of $\mathrm{As}(\mathrm{V})$ was prepared by dissolving $4.1652 \mathrm{~g}$ of sodium arsenate heptahydrate (FW $=302.01$, Fisher Scientific) in 11 of $10 \% \mathrm{v} \mathrm{v}^{-1}\left(4.4 \% \mathrm{~m} \mathrm{~m}^{-1}\right)$ hydrochloric acid. As(V) standards were prepared by diluting this stock solution appropriately with $10 \% v^{-1}$ hydrochloric acid. Nickel(II) 


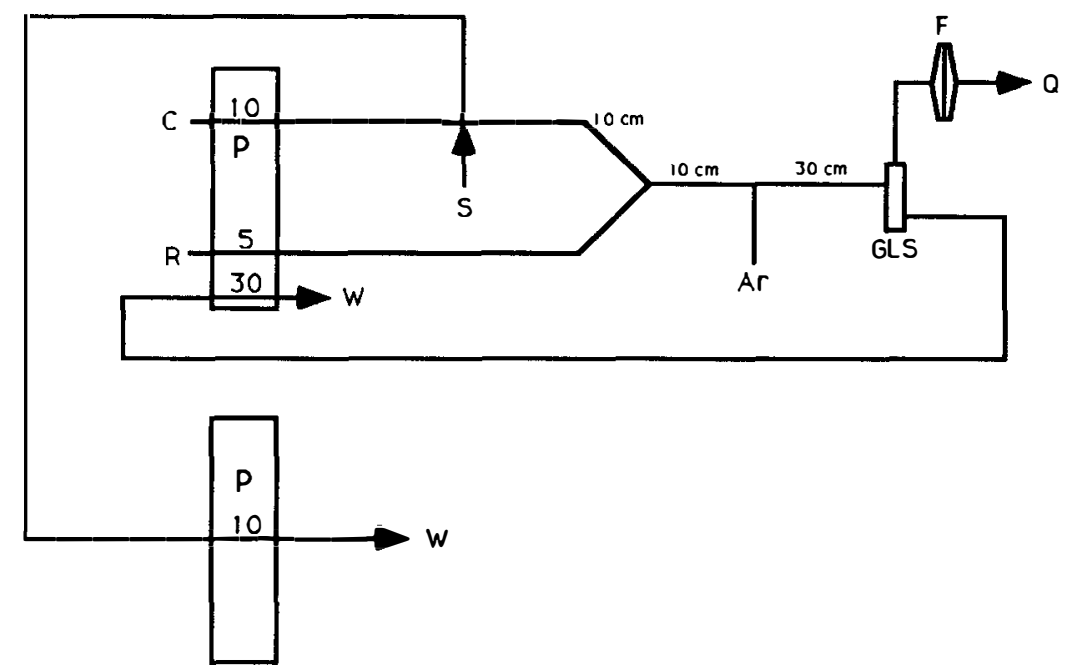

Fig. 1. Optimized FI hydride-generation AAS manifold for arsenic determinations in a nickel alloy. All manifold tubing is $1.0 \mathrm{~mm}$ i.d. C: carrier stream; R: reductant stream; S: sample injected; W: waste; P: pump; GLS: gas-liquid separator; F: $1 \mu \mathrm{m}$ pore size PTFE syringe filter; Q: quartz atomization cell $\left(900^{\circ} \mathrm{C}\right)$; and Ar: argon purge stream $\left(30 \mathrm{ml} \mathrm{min}^{-1}\right)$. Reagent flow rates are shown on the pumps in $\mathrm{ml} \mathrm{min}^{-1}$.

nitrate hexahydrate $(\mathrm{FW}=290.80$, Fisher Scientific) was used for the preparation of interference standards. High purity argon (Linde) was used as the purge gas. Reagent grade concentrated nitric acid $\left(70 \% \mathrm{~m} \mathrm{~m}^{-1}\right.$, density $=1.42$, Fisher Scientific) and reagent grade hydrofluoric acid $\left(48 \% \mathrm{~m} \mathrm{~m}^{-1}\right.$, density $\left.=1.15, \mathrm{BDH}\right)$ were used for the alloy digestion. The alloy sample was British Chemical Standard (BCS) Certified Reference Material (CRM) \#346 IN 100 nickel alloy $\left(60 \% \mathrm{~m} \mathrm{~m}^{-1}\right.$ nickel content) obtained through the Bureau of Analyzed Samples Ltd.

\subsection{Alloy digestion procedure}

The procedure used for digestion of the alloy is identical to the microwave digestion reported by RIBY et al. [17]. A portion of the alloy sample $(1 \mathrm{~g})$ was placed in a microwave digestion vessel (CEM Corporation) with $20 \mathrm{ml}$ of $4 \% \mathrm{v} \mathrm{v}^{-1}\left(4.0 \% \mathrm{~m} \mathrm{~m}^{-1}\right)$ ntric acid and $2.5 \mathrm{ml}$ of $48 \% \mathrm{~m} \mathrm{~m}^{-1}$ hydrofluoric acid. The digestion vessels were heated in a microwave oven (CEM Corporation) according to the digestion procedure shown in Table 1. A total of six digestion vessels were used in each digestion to act as power regulators. Once the vessels were cooled, the resulting digest solutions were diluted to $100 \mathrm{ml}$ with pure water. Aliquots of these solutions were then diluted 100 -fold with $10 \% v^{-1}$ hydrochloric acid prior to analysis. This resulted in a nickel concentration of $60 \mu \mathrm{g} \mathrm{ml}^{-1}$ in the analyzed sample.

\subsection{Optimization of manifold parameters}

The design of the manifold was such that optimum sensitivity for a $10 \mathrm{ng} \mathrm{ml}^{-1} \mathrm{As}(\mathrm{V})$ standard solution was obtained, while keeping transition metal interference effects to a minimum. To

Table 1. Microwave digestion program for digestion of a nickel alloy*

\begin{tabular}{lcc}
\hline Step & Power (\%) & Time $(\mathrm{min})$ \\
\hline 1 & 30 & 15 \\
2 & 50 & 15 \\
3 & 40 & 30 \\
\hline
\end{tabular}

* A total of six digestion vessels were run at once, to act as excess power regulators. 


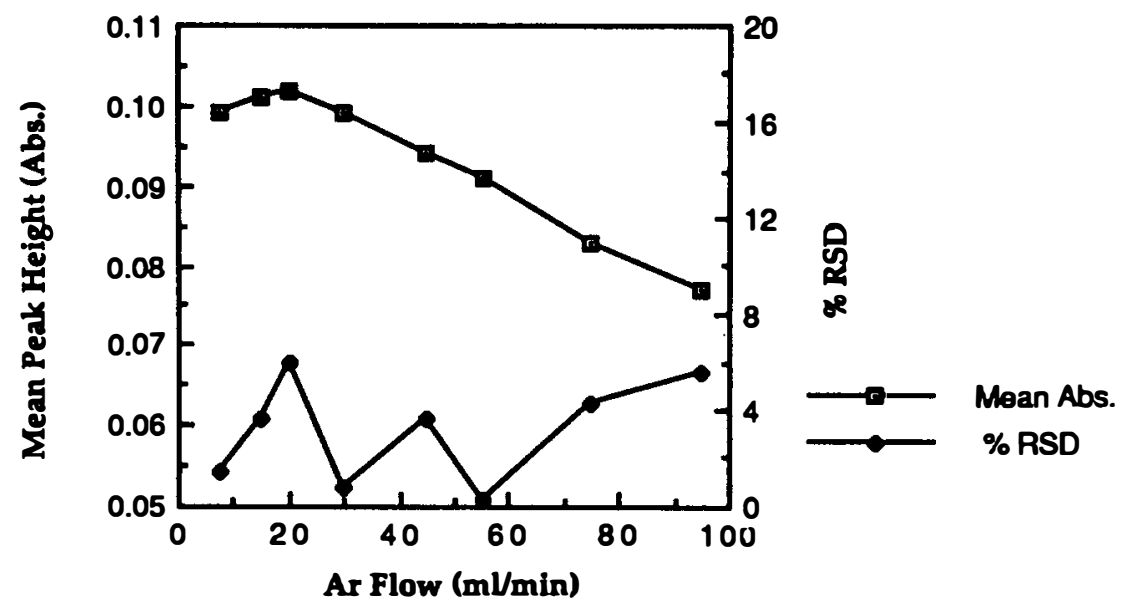

Fig. 2. Effect of argon flow rate on the arsenic signal. Thirty $\mathrm{ml} \mathrm{min}^{-1}$ is the best compromise between precision and sensitivity. $[A s(V)]=10 \mathrm{ng} \mathrm{ml}^{-1}$.

obtain optimum sensitivity for $\mathrm{As}(\mathrm{V})$, the variables of argon flow, atomization cell temperature, reaction coil length and acid concentration were examined. To minimize nickel(II) interference effects, the variables of reaction coil length, acid strength and sodium borohydride strength were examined.

\subsection{Analysis procedure}

The final system was calibrated with a series of $\operatorname{As}(\mathrm{V})$ standards covering the range of 1 to $25 \mathrm{ng} \mathrm{ml}^{-1}$. Once the calibration was complete, the analysis of the alloy was performed directly by injecting the diluted alloy digest into the system. A $500 \mu \mathrm{l}$ injection volume was used for both calibration and alloy digest analysis.

\section{RESULTS}

\subsection{Optimization of the FI hydride-generation manifold}

3.1.1. Optimization of $\mathrm{As}(\mathrm{V})$ sensitivity. The effect of argon flow was investigated over the range 10-100 $\mathrm{ml} \mathrm{min}^{-1}$. The best compromise between peak height and peak precision is obtained at $30 \mathrm{ml} \mathrm{min}{ }^{-1}$. Sensitivity and precision gradually deteriorated as the argon flow was increased above $30 \mathrm{ml} \mathrm{min}^{-1}$. This is shown in Fig. 2.

The atomization temperature of the quartz cell was investigated over the range $600-1000^{\circ} \mathrm{C}$. It was found that the serisitivity was for the most part constant at temperatures $\geq 700^{\circ} \mathrm{C}$, with the maximum sensitivity obtained at $900^{\circ} \mathrm{C}$ and a gradual decrease in sensitivity at temperatures above $900^{\circ} \mathrm{C}$. Therefore, $900^{\circ} \mathrm{C}$ was found to be the optimum atomization temperature.

The reaction tube length between the acid/borohydride confluence point and the point of argon addition was examined over the range $10-200 \mathrm{~cm}$. It is shown in Fig. 3 that increasing the reaction coil length increased the sensitivity for $\mathrm{As}(\mathrm{V})$. This trend correlates with the findings of other investigators $[8,24]$. Practical limitations were encountered for reaction tube lengths greater than $200 \mathrm{~cm}$-such as increased back pressure and pulsations within the system.

The effect of carrier acidity was examined over the range $10-80 \% \mathrm{v} \mathrm{v}^{-1}$ $\left(4.4 \%-31.4 \% \mathrm{~m} \mathrm{~m}^{-1}\right)$ hydrochloric acid. When the acid concentration was increased, there was an increase in sensitivity for $\operatorname{As}(V)$. This trend also correlates with the findings of other investigators $[8,24,25]$. The effect of carrier acidity is shown in Fig.4.

3.1.2. Optimization of $\mathrm{Ni}(\mathrm{II})$ interference tolerance. It was found by WeLz and SCHUBERT-JACOBS [26] that the tolerance for interfering transition metals in hydridegeneration AAS can be increased by minimizing the amount of borohydride used in the reduction. The amount of borohydride used in the reduction was initially set at 


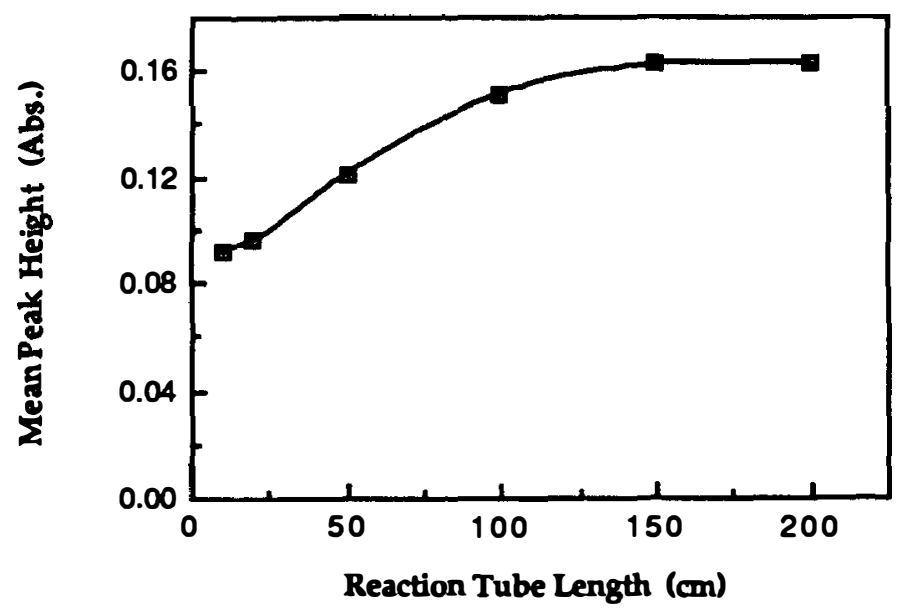

Fig. 3. Effect of reaction tube length on the signal for $10 \mathrm{ng} \mathrm{ml}^{-1} \mathrm{As}(\mathrm{V})$.

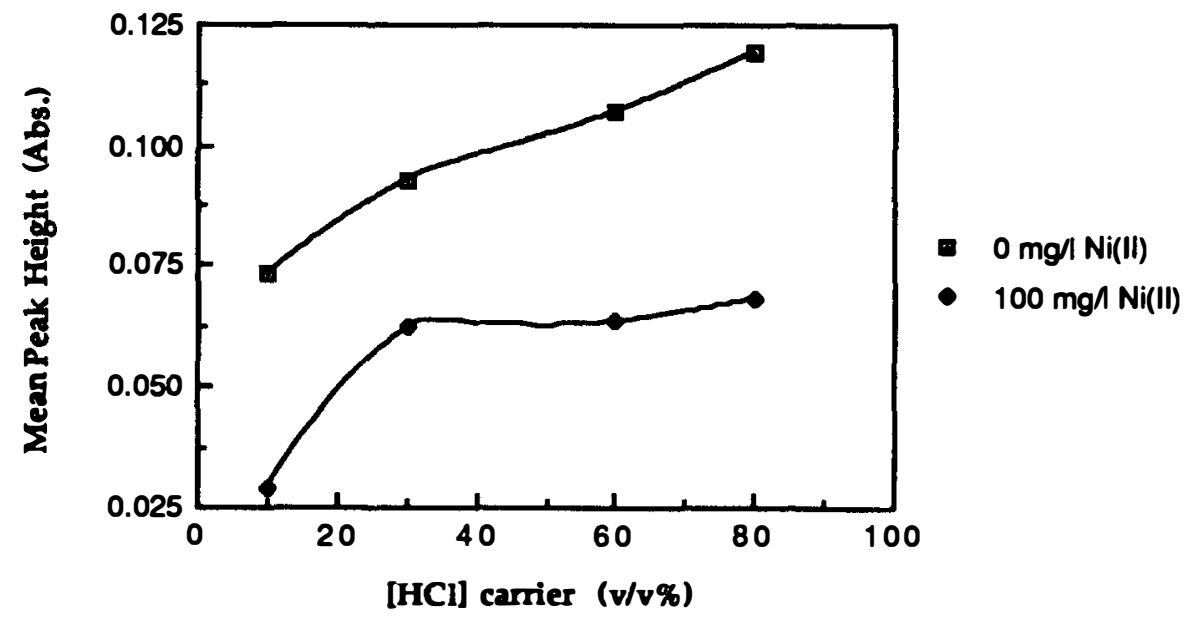

Fig. 4. Effect of carrier acidity on the signal for $10 \mathrm{ng} \mathrm{ml}^{-1}$ of $\mathrm{As}(\mathrm{V})$, with and without $\mathrm{Ni}(\mathrm{II})$ present in the sample.

$1.0 \%\left(\mathrm{~m} \mathrm{v}^{-1}\right)$ sodium borohydride in $0.1 \%\left(\mathrm{~m} \mathrm{v}^{-1}\right)$ sodium hydroxide. At the higher carrier acidities tested ( $\geq 60 \% \mathrm{v} \mathrm{v}^{-1}, 24.3 \% \mathrm{~m} \mathrm{~m}^{-1}$ hydrochloric acid), it was found that decreasing the sodium borohydride concentration resulted in the absence of any signal whatsoever. For this reason, it was decided that $1.0 \%$ sodium borohydride was the minimum amount of reductant that could be used for both high and low acidity carrier streams. There were no further attempts at optimizing the sodium borohydride concentration.

The effect of carrier acidity on the tolerance of nickel(II) interferent was examined. As in the case of nickel(II) being absent, the sensitivity for As(V) increased with increasing carrier acidity for the nickel(II)-spiked $\mathrm{As}(\mathrm{V})$ standards. This is also shown in Fig. 4. However, when the sensitivity for the $100 \mu \mathrm{g} \mathrm{ml} \mathrm{m}^{-1}$ nickel(II)-spiked As(V) standard is compared relative to the non-spiked $\mathrm{As}(\mathrm{V})$ standard for the same carrier acidity, a rather interesting trend is observed. While the maximum sensitivity for As(V) without nickel(II) present is realized with a carrier acidity of $80 \% \mathrm{v} \mathrm{v}^{-1}\left(31.4 \% \mathrm{~m} \mathrm{~m}^{-1}\right)$ hydrochloric acid, the maximum interference tolerance is at a carrier acidity of $30 \% v^{-1}\left(12.8 \% \mathrm{~m} \mathrm{~m}^{-1}\right)$ hydrochloric acid. This is shown in Fig. 5. This may be due to acidities greater than $30 \% \mathrm{v} \mathrm{v}^{-1}$ leading to detrimentally excessive hydrogen formation, thus diluting the hydride in the vapor phase or increasing back pressure within the low volume gas-liquid separator. A previous optimization study [18] has shown that increasing the sample acidity instead of the carrier acidity will also lead to 


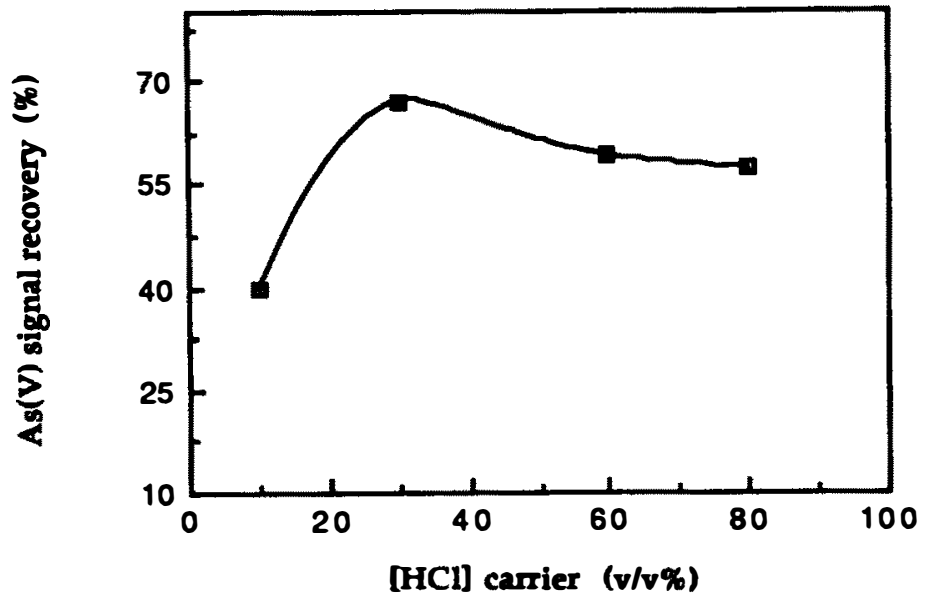

Fig. 5. Effect of carrier acidity on the tolerance of $100 \mathrm{mg} \mathrm{ml}^{-1} \mathrm{Ni}(\mathrm{II})$ interferent present in $10 \mathrm{ng} \mathrm{ml}^{-1} \mathrm{As}(\mathrm{V})$.

an increased interference tolerance. However, further sample acidification would be unrealistic in this case since it may contribute to the blank As value, as well as making approximate acid matching of samples and standards more difficult.

The reaction tube length was investigated for its effect on the tolerance of nickel(II) interferent. It was shown earlier that increasing the length of the reaction tube increased the sensitivity for $\mathrm{As}(\mathrm{V})$ when no nickel(II) was present. However, it was later shown that increasing the reaction tube length led to a decreased tolerance for nickel(II) in the sample. It was decided to minimize the length of the reaction tube to $10 \mathrm{~cm}$, since this allows for maximum nickel(II) tolerance while still allowing sufficient sensitivity for $\mathrm{As}(\mathrm{V})$.

\subsection{Analysis of nickel alloy reference material BCS-CRM \#346}

The nickel alloy sample was digested in a microwave oven using a procedure identical to that described by RIBY et al. [17]. These investigators recommend diluting the final digestion solution 25 -fold to lower the concentration of nickel(II) present. However, it was decided to dilute the final digestion solution 100 -fold with $10 \% \mathrm{v} \mathrm{v}^{-1}$ $\left(4.4 \% \mathrm{~m} \mathrm{~m}^{-1}\right)$ hydrochloric acid instead. This brought the nickel(II) to a concentration that was theorized to be tolerable $\left(60 \mu \mathrm{g} \mathrm{ml}^{-1}\right)$, while still leaving the As(V) at a concentration $\left(5 \mathrm{ng} \mathrm{ml}^{-1}\right)$ that could be measured with a good degree of confidence. Furthermore, this extra dilution with $10 \% v^{-1}$ hydrochloric acid allowed for approximate acid matching to be made between standards and the sample, as shown in Table 2. After this dilution, the digestion blank was found to contain no determinable As. The certified value for the presence of arsenic in the reference material is $50.2 \pm 3.2 \mu \mathrm{g} \mathrm{g}^{-1}$. This method determined the arsenic content to be $49.6 \pm 3.3 \mu \mathrm{g}$ $\mathrm{g}^{-1}$. Optimized conditions for the analysis of the nickel alloy using the FIAS 200 for arsine generation are shown in Table 3.

Table 2. Acid content of standards and digested alloy sample at point of analysis.

Concentrations shown are $v v^{-1}$

As(V) Standard Digested Alloy Sample

$10 \% \mathrm{HCl} \quad 10 \% \mathrm{HCl}$

$0.025 \%$ HF

$0.008 \% \mathrm{HNO}_{3}$ 
Table 3. Optimized variables for FI hydride-generation AAS for the determination of arsenic in a nickel alloy using the Perkin-Elmer FIAS 200 system

\begin{tabular}{lcr}
\hline Reagent & Concentration & Flow Rate $\left(\mathrm{ml} \mathrm{min}^{-1}\right)$ \\
\hline $\mathrm{HCl}$ carrier & $30 \%\left(\mathrm{v} \mathrm{v}^{-1}\right)$ & 10 \\
$\mathrm{NaBH}_{4}$ reductant & $1.0 \%\left(\mathrm{~m} \mathrm{v}^{-1}\right)$ in $0.1 \%\left(\mathrm{~m} \mathrm{v}^{-1}\right) \mathrm{NaOH}$ & 5 \\
Standard diluent & $10 \%\left(\mathrm{v} \mathrm{v}^{-1}\right) \mathrm{HCl}$ & - \\
Ar purge & - & 30 \\
\hline
\end{tabular}

Injection Volume $=500 \mu \mathrm{l}$

$10 \mathrm{~cm} \times 1 \mathrm{~mm}$ i.d. reaction tube

$30 \mathrm{~cm} \times 1 \mathrm{~mm}$ i.d. stripping tube

\section{Discussion}

It is clear that to get the best performance from a system an optimization is required. As the conditions chosen are somewhat different from those recommended by the manufacturer, a sensible strategy would appear to be to use these recommended values for any search of the factor space. It is difficult to compare the sensitivity of the resulting method with that of previously published methods as all of these measure arsenic after pre-reduction to the trivalent oxidation state. However, as the sensitivity for $\mathrm{As}(\mathrm{V})$ is about $20-25 \%$ of that of $\mathrm{As}(\mathrm{III})$, it may be calculated that the procedure developed is significantly more sensitive than other flow injection procedures described recently $[17,23]$. It is considered that a major factor in achieving this increased sensitivity is the reduced volume of the gas-liquid separator included as a hydridegeneration accessory in the FIAS 200 system. This gas-liquid separator has a total dead volume more than an order of magnitude less than some commonly used gas-liquid separators [27]. Thus, as the dilution in the gas phase is considerably less, the sensitivity for $\mathrm{As}(\mathrm{V})$ is enhanced almost an order of magnitude. A further contributory factor to the reduced gas-phase dispersion is the use of narrow bore tubing ( $1 \mathrm{~mm}$ i.d.) connecting the separator to the atomization cell. The increased sensitivity allows the alloy digest solution to be diluted to an extent such that the interfering element is at a tolerable concentration, while retaining the ability to detect $\mathrm{As}(\mathrm{V})$ without pre-reduction.

\section{Conclusions}

The optimization of a FI hydride generation system in terms of the chemical operating parameters produces further benefits, in terms of both sensitivity and interference tolerance, over those achieved by optimization of the manifold parameters only. This improved performance considerably simplifies the method when compared with previously published FI hydride generation procedures for the determination of As in nickel alloy materials $[17,23]$. It is considered likely that the determination of other hydride forming elements in the presence of potentially interfering matrices may be similarly simplified.

Acknowledgements_-Financial support for S. G. Offley and C. P. HanNA from the Science and Engineering Research Council, U.K. and Perkin-Elmer Corporation, Norwalk, CT, U.S.A., respectively is gratefully acknowledged.

\section{REFERENCES}

[1] T. Nakahara, Prog. Anal. At. Spectrosc. 6, 163 (1983).

[2] J. Dědina, Prog. Anal. Spectrosc. 11, 251 (1988).

[3] B. Welz and M. Melcher, Analyst 109, 569 (1984).

[4] B. Welz and M. Melcher, Analyst 109, 573 (1984).

[5] P. N. Vijan and C. Y. Chan, Anal. Chem. 48, 1788 (1976).

[6] F. D. Pierce and H. R. Brown, Anal. Chem. 49, 1417 (1977).

[7] O. Astrom, Anal. Chem. 54, 190 (1982). 
[8] M. Yamomoto, M. Yasuda and Y. Yamomoto, Anal. Chem. 57, 1382 (1985).

[9] C. Y. Chan, Anal. Chem. 57, 1482 (1985).

[10] Z. Fang, S. Xu, W. Wang and S. Zhang, Anal. Chim. Acta 179, 325 (1986).

[11] T. Guo, W. Erler, H. Schulze and S. McIntosh, At. Spectrosc. 11, 24 (1990).

[12] J. A. C. Broekaert, Spectrochim. Acta 45B, 845 (1990).

[13] J. F. Tyson, Spectrochim. Acta Rev. 14, 169 (1991).

[14] S. N. Willie, R. E. Sturgeon and S. S. Berman, Anal. Chem. 58, 1140 (1986).

[15] B. Welz and M. Melcher, Analyst 108, 213 (1983).

[16] M. Yamomoto, K. Takada, T. Kumamaru, M. Yasuda, S. Yokoyama and S. Yamomoto, Anal. Chem. 59, 2446 (1987).

[17] P. G. Riby, S. J. Haswell and R. Grezeskowiak, J. Anal. At. Spectrom. 4, 181 (1989).

[18] B. Welz and M. Schubert-Jacobs, At. Spectrosc. 12, 91 (1991).

[19] J. C. Miller and J. N. Miller, Statistics for Analytic Chemistry, 2nd Edn, p. 179. Ellis Horwood, Chichester (1988).

[20] S. G. Offley, Ph.D. thesis, University of Technology, Loughborough, U.K. (1992).

[21] S. Greenfield, M. S. Salman, M. Thomsen and J. F. Tyson, J. Anal. At. Spectrom. 4, 55 (1989).

[22] S. G. Offley, N. J. Seare, J. F. Tyson and H. A. B. Kibble, J. Anal. At. Spectrom. 6, 133 (1991).

[23] J. F. Tyson, S. G. Offley, N. J. Seare, H. A. B. Kibble and C. Fellows. J. Anal. At. Spectrom. 7, 315 (1992).

[24] M. Ikeda, Anal. Chim. Acta 167, 289 (1985).

[25] J. Aggett and A. C. Aspell, Analyst 101, 341 (1976).

[26] B. Welz and M. Schubert-Jacobs, J. Anal. At. Spectrom. 1, 23 (1986).

[27] M. Thompson, B. Pahlavanpour, S. J. Walton and G. F. Kirkbright, Analyst 103, 568 (1978). 